\title{
Exercise ventilation after balloon dilatation of the mitral valve
}

\author{
Adrian P Banning, Neil P Lewis, J Stuart Elborn, Roger J C Hall
}

\begin{abstract}
Background-Exertional dyspnoea is a limiting symptom in many patients with mitral stenosis but its causes remain incompletely understood. Ventilation during exercise is abnormal in chronic heart failure of all causes and there is increased ventilatory cost of carbon dioxide production.
\end{abstract}

Patients-23 patients with rheumatic mitral stenosis undergoing percutaneous balloon dilatation of the mitral valve were studied to investigate exercise ventilation.

Methods-Treadmill exercise tests with respiratory gas analysis were performed before and 1 day, 7 days, and 10 weeks after balloon dilatation of the mitral valve. The relation between ventilation ( $\dot{V} E)$ and production $\left(\dot{\mathrm{V}} \mathrm{CO}_{2}\right)$ was analysed by linear regression.

Results-The $\dot{\mathbf{V}} / \mathbf{V} \mathrm{CO}_{2}$ slope was linear in all patients and before balloon dilatation of the mitral valve it correlated inversely with peak minute oxygen consumption $\left(\dot{\mathbf{V}} \mathrm{O}_{2}\right) \quad\left(\boldsymbol{r}_{\mathrm{s}}=-0.47, \quad \mathrm{P}<0.05\right)$, exercise duration $\left(r_{\mathrm{s}}=-0.66, \quad \mathrm{P}<0.01\right)$, and mitral valve area $\left(r_{\mathrm{s}}=-0.5, P<0.05\right)$. The $\dot{\mathbf{V}} \mathbf{E} / \dot{V} \mathrm{CO}_{2}$ slope declined acutely after balloon dilatation of the mitral valve (n= 10) (mean (SD) 41 (4) $v 36(2 \cdot 9), \mathbf{P}<$ $0 \cdot 05)$ and did not change again thereafter. At 10 weeks $(n=23)$ exercise duration (460 (230) $v 630(240) \mathrm{s}, \mathrm{P}<0.01)$ and peak $\dot{\mathrm{V}} \mathrm{O}_{2}(12 \cdot 7(4 \cdot 3)$ v $14.9(4 \cdot 8) \mathrm{ml} / \mathrm{kg} /$ min, $P<0.05)$ increased significantly. Conclusions-Patients with rheumatic mitral stenosis have a similar increase in the $\dot{\mathbf{V}} / \dot{V} \mathrm{CO}_{2}$ slope to that of patients with heart failure from other causes. Successful balloon dilatation of the mitral valve is associated with an acute reduction in the exercise $\dot{\mathrm{V}} \mathrm{E} / \dot{\mathrm{V}} \mathrm{CO}_{2}$ slope.

(Br Heart f 1995;73:386-389)

Keywords: balloon dilatation of the mitral valve; exercise ventilation; chronic heart failure; mitra stenosis

The haemodynamic changes that occur during exercise in patients with mitral stenosis are well documented ${ }^{1}$ but the causes of exertional hyperpnoea have never been fully elucidated. Possible causes including enhanced central respiratory drive, reduced lung compliance, and pulmonary congestion leading to stimula- tion of juxtapulmonary capillary receptors have been suggested. ${ }^{2}$

The ventilatory response to exercise is abnormal in chronic heart failure (CHF) of all causes. ${ }^{3}$ There is an excess ventilatory cost of carbon dioxide $\left(\mathrm{CO}_{2}\right)$ production and this is reflected by an increase in the slope of the linear relation between $\mathrm{CO}_{2}$ production and ventilation. ${ }^{45}$ This increase in slope is related directly to exercise capacity at levels of peak minute oxygen consumption $\left(\mathrm{V}_{2}\right)$ $<20 \mathrm{ml} / \mathrm{kg} / \mathrm{min}^{4}$ and reflects increased physiological dead space ventilation.

Patients with mitral stenosis have increased ventilation of physiological dead space at rest. ${ }^{6}$ Unlike conventional surgical treatment for mitral stenosis, percutaneous balloon dilatation of the mitral valve allows assessment of exercise dynamics immediately after palliation of valve disease, without confounding postoperative changes. We have investigated hyperpnoea in mitral stenosis by observing the time course of changes in cardiorespiratory function after balloon dilatation of the mitral valve and their temporal relation to improvement in exercise haemodynamics.

\section{Patients and methods \\ PATIENTS}

The study population consisted of 23 patients (22 women; mean (SD) (range) age (58 (10) (44-74) years) with rheumatic mitral stenosis undergoing routine balloon dilatation of the mitral valve. Two patients were in New York Heart Association class II for heart failure, 19 in class III, and two in class IV. All patients had normal coronary arteries and a left ventricular ejection fraction $>40 \%$ on angiography (normal range 55-70\%). Patients with aortic valve disease, evidence of bronchopulmonary disease, or other serious medical conditions were excluded. Medication was continued unchanged throughout the study and is summarised in table 1 .

\section{STUDY PROTOCOI}

Consecutive patients $(n=23)$ performed maximal exercise testing $24 \mathrm{~h}$ before balloon dilatation of the mitral valve and 10 (range 9-15) weeks after the procedure. Table 1 gives patient details. Ten consecutive unselected patients (nine women; mean (SD) (range) age $60(10)(45-70)$ years) also performed exercise tests at $24 \mathrm{~h}$ and 10 days after the procedure. Exercise testing at $24 \mathrm{~h}$ was submaximal and limited to $75 \%$ of the 
Table 1 Patient population

\begin{tabular}{|c|c|c|c|c|c|c|c|}
\hline \multirow[b]{2}{*}{ Case } & \multirow[b]{2}{*}{ Sex } & \multirow[b]{2}{*}{$\begin{array}{l}\text { Age } \\
\text { (years) }\end{array}$} & \multirow[b]{2}{*}{ Rhythm } & \multirow[b]{2}{*}{ Treatment } & \multicolumn{2}{|l|}{$M V A$} & \multirow[b]{2}{*}{$\begin{array}{l}P A P \\
(m m ~ H g\end{array}$} \\
\hline & & & & & $\begin{array}{l}\text { Before } \\
\left(\mathrm{cm}^{2}\right)\end{array}$ & $\begin{array}{l}\text { Immediately } \\
\text { after } \\
\left(\mathrm{cm}^{2}\right)\end{array}$ & \\
\hline 1 & $\mathbf{F}$ & 63 & AF & W,D,F & 1.02 & $1 \cdot 29$ & 46 \\
\hline 2 & $\mathbf{F}$ & 46 & SR & $\mathbf{F}$ & 0.9 & 1.5 & 40 \\
\hline 3 & $\mathbf{F}$ & 44 & SR & W,F,A & $1 \cdot 3$ & 2.09 & 44 \\
\hline 4 & $\mathbf{F}$ & 45 & AF & $\mathrm{W}, \mathrm{D}, \mathrm{F}$ & 1.08 & $1 \cdot 75$ & 45 \\
\hline 5 & $\mathbf{F}$ & 58 & $\mathrm{AF}$ & $\mathrm{W}, \mathrm{D}, \mathrm{F}$ & 0.7 & $1 \cdot 3$ & 55 \\
\hline 6 & $\mathrm{~F}$ & 58 & SR & F & $1 \cdot 17$ & $1 \cdot 73$ & 30 \\
\hline 7 & $\mathbf{F}$ & 55 & $\mathrm{AF}$ & W,D,F & $1 \cdot 4$ & $2 \cdot 2$ & 45 \\
\hline 8 & $\mathbf{F}$ & 53 & AF & $\mathrm{D}, \mathrm{F}$ & 0.95 & 1.63 & 57 \\
\hline 9 & $\mathbf{F}$ & 52 & $\mathrm{AF}$ & $\mathrm{D}, \mathrm{F}$ & $0 \cdot 8$ & $1 \cdot 8$ & 50 \\
\hline 10 & $\mathbf{F}$ & 74 & AF & W,D,F & $0 \cdot 85$ & $1 \cdot 4$ & 30 \\
\hline 11 & $\mathbf{F}$ & 54 & $\mathrm{AF}$ & W,D & $1 \cdot 17$ & 1.6 & 38 \\
\hline $12^{\star}$ & F & 70 & $\mathrm{AF}$ & W,D,F & 0.83 & 1.07 & 51 \\
\hline $13^{\star}$ & $\mathrm{F}$ & 67 & $\mathrm{AF}$ & W,D,F & $0 \cdot 8$ & $1 \cdot 34$ & 40 \\
\hline $14^{\star}$ & $\mathbf{M}$ & 60 & $\mathrm{AF}$ & W,D,F & 0.6 & $1 \cdot 3$ & 70 \\
\hline 15 & $\mathbf{F}$ & 71 & $\mathrm{AF}$ & $\mathrm{W}, \mathrm{D}, \mathrm{F}$ & 0.7 & $0 \cdot 8$ & 46 \\
\hline 16 & $\mathbf{F}$ & 60 & SR & W,F & 1.08 & 1.08 & 70 \\
\hline $17^{\star}$ & $\mathbf{F}$ & 70 & AF & W,D,F & 0.73 & 1.05 & 50 \\
\hline $18^{\star}$ & $\mathbf{F}$ & 45 & AF & W,D,F & $0 \cdot 81$ & 1.58 & 57 \\
\hline $19^{\star}$ & $\mathbf{F}$ & 46 & SR & - & 0.92 & $1 \cdot 13$ & 46 \\
\hline $20^{\star}$ & $\mathbf{F}$ & 55 & $\mathrm{AF}$ & W,D,F & $0 \cdot 7$ & $1 \cdot 2$ & 36 \\
\hline $21^{\star}$ & $\mathbf{F}$ & 61 & $\mathrm{AF}$ & W,D,F & 0.65 & 1 & 26 \\
\hline $22^{\star}$ & $\mathbf{F}$ & 72 & $\mathrm{AF}$ & W,D,F & 0.64 & 0.64 & 50 \\
\hline $23^{\star}$ & $\mathbf{F}$ & 58 & SR & $\mathrm{F}, \mathrm{A}$ & 0.9 & $1 \cdot 2$ & 44 \\
\hline
\end{tabular}

^Patients exercised at $24 \mathrm{~h}, 10$ days, and 10 weeks after balloon dilatation of the mitral valve. $A F$, atrial fibrillation; $S R$, sinus rhythm; W, warfarin; D, digoxin; F, frusemide; $A$, angiotensin converting enzyme inhibitor; MVA, mitral valve area (Gorlin); PAP, systolic pulmonary artery pressure measured before balloon dilatation of the mitral valve.

maximum workload, before balloon dilatation of the mitral valve, in view of recent femoral arterial cannulation. All participants gave informed consent.

\section{EXERCISE TESTING}

After familiarisation patients performed progressive symptom limited exercise testing using the Weber et al protocol. ${ }^{7}$ Expired respiratory gases were collected and passed to a mass spectrometer (Airspec 2000; Airspec, Bromley, Kent). Argon dilution was used to give on line measurement of minute ventilation $(\dot{V} E)$, minute $\mathrm{CO}_{2}$ production $\left(\dot{\mathrm{V}}_{2}\right)$, and $\dot{\mathrm{VO}}_{2}$. Peak $\dot{\mathrm{VO}}_{2}$ was determined from the mean $\mathrm{VO}_{2}$ over the final $30 \mathrm{~s}$ of exercise. The relation during exercise between $\dot{\mathrm{VE}}$ and $\dot{\mathrm{V}} \mathrm{CO}_{2}$ (plotted every $15 \mathrm{~s}$ ) was analysed by linear regression.

PERCUTANEOUS BALLOON DILATATION OF THE MITRAL VALVE

Cardiac output was measured using the Fick method and mitral valve area was calculated using the Gorlin formula. Balloon dilatation of the mitral valve was performed using the Inoue et al technique ${ }^{8}$ without complication. Table 1 presents the changes in mitral valve area. Measurements after balloon dilatation of the mitral valve were repeated with the balloon catheter in place across the atrial septum. This avoided the possibility of a spurious increase in mitral valve area induced by the small left to right shunt.

\section{STATISTICAL ANALYSIS}

Data are reported as group mean (SD). The significance of differences was tested using non-parametric statistical analysis (Wilcoxon signed rank for paired data and MannWhitney U for unpaired data). Correlation's were examined using the Spearman's rank test $\left(r_{\mathrm{s}}\right)$. A p value $<0.05$ was considered significant.

\section{Results}

EXERCISE TESTING BEFORE BALLOON

DILATATION OF THE MITRAL VALVE

The limiting symptom in the 23 patients was breathlessness. Figure 1 shows a representative example of the exercise relation between $\dot{\mathrm{V}} \mathrm{E}$ and $\dot{\mathrm{VCO}}_{2}$. The $\dot{\mathrm{VE}} / \dot{\mathrm{V}} \mathrm{CO}_{2}$ slope was linear in all patients ( $r>0.92$ in every test) and, as in chronic heart failure from other causes, it correlated inversely with peak $\mathrm{VO}_{2} \mathrm{ml} / \mathrm{kg} / \mathrm{min}$ (fig $2, r_{\mathrm{s}}=-0.47, \mathrm{P}<0.05$ ). The $\dot{\mathrm{V}} / \dot{\mathrm{VCO}}_{2}$ slope also correlated inversely with exercise duration (fig 3, $r_{\mathrm{s}}=-0.66, \mathrm{P}<0.01$ ) and with mitral valve area measured before balloon dilatation of the mitral valve (fig 4 , $\left.r_{\mathrm{s}}=-0.5, \mathrm{P}<0.05\right)$. There was no relation between $\dot{\mathrm{VE}} / \dot{\mathrm{VCO}}_{2}$ slope and pulmonary artery systolic pressure.

\section{EXERCISE TESTING AFTER BALLOON}

DILATATION OF THE MITRAL VALVE

Submaximal exercise testing at $24 \mathrm{~h}(\mathrm{n}=10)$ was performed without complication. The

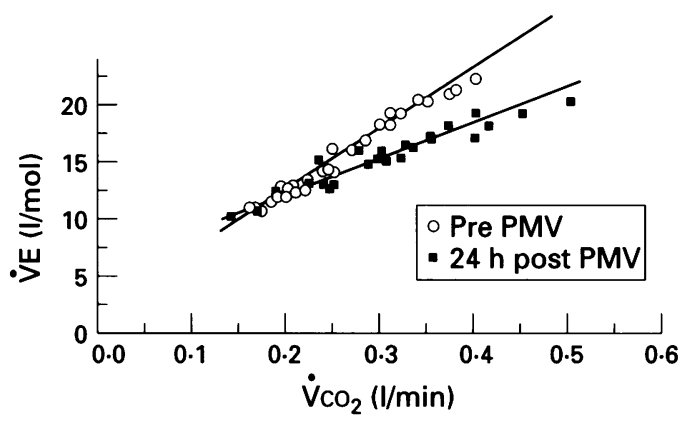

Figure 1 Representative example of a patient's $\dot{V} E / \dot{V}_{C}$ slope relation before and $24 h$ after balloon dilatation of the mitral valve (PMV).

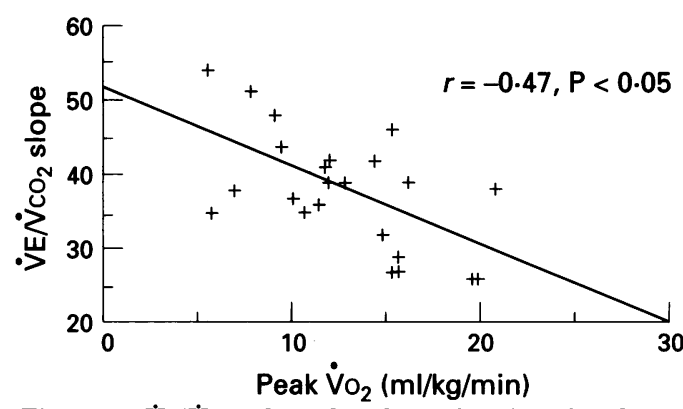

Figure $2 \quad \dot{V} E / \dot{V} \mathrm{O}_{2}$ slope plotted as a function of peak $\dot{V} \mathrm{O}_{2}$ in 23 patients with mitral stenosis before balloon dilatation of the mitral valve.

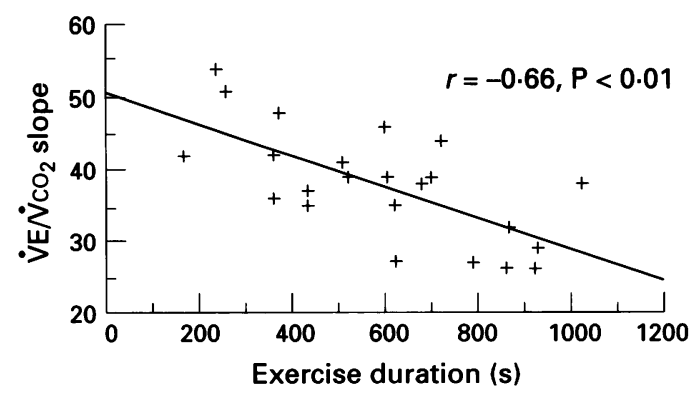

Figure $3 \quad \dot{V} E / \dot{V}_{\mathrm{CO}_{2}}$ slope plotted as a function of exercise duration in 23 patients with mitral stenosis before balloon dilatation of the mitral valve. 
Figure $4 \quad \dot{V} E / \dot{V} \mathrm{CO}_{2}$ slope plotted as a function of mitral valve area in 23 patients with mitral stenosis before balloon dilatation of the mitral valve.

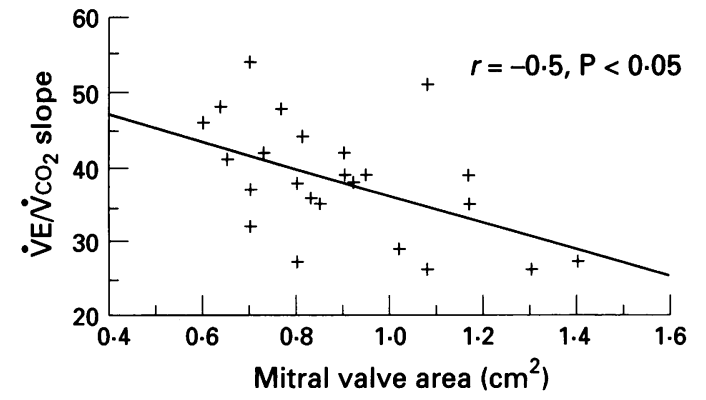

$\mathrm{VE} / \mathrm{VCO}_{2}$ slope, peak $\mathrm{Vo}_{2}$, and exercise duration were significantly lower after balloon dilatation of the mitral valve (table 2). Maximal exercise testing at 10 days documented an increase in exercise duration and peak $\mathrm{VO}_{2}$ but no further change in the $\dot{\mathrm{VE}} / \dot{\mathrm{V}} \mathrm{CO}_{2}$ slope. The respiratory exchange ratio at maximum exercise was $>1.0$ in all patients. Figure 5 shows the change in $\dot{\mathrm{VE}} / \mathrm{V} \mathrm{CO}_{2}$ slope after balloon dilatation of the mitral valve.

Twenty of 23 patients reported an improvement in their symptoms of exertional dyspnoea 10 weeks after balloon dilatation of the mitral valve. Repeat exercise testing in 23 patients demonstrated significant increases in exercise duration (from $460(230)$ to 630 (240) s, $\mathrm{P}<0.01)$ and peak $\dot{\mathrm{Vo}}_{2}(12.7(4.3) v$ $14.9(4.8) \mathrm{ml} / \mathrm{kg} / \mathrm{min}, \quad P<0.05)$ compared with the baseline before balloon dilatation of the mitral valve. The $\dot{\mathrm{VE}} / \mathrm{V} \mathrm{CO}_{2}$ slope was significantly reduced (from 38 (7) to 34 (9), $\mathrm{P}<0.01$ ), but remained inversely correlated with peak $\dot{\mathrm{VO}}_{2}\left(r_{\mathrm{s}}=-0.62, \mathrm{P}<0.01\right)$. A weak non-significant correlation existed between absolute change in valve area and reduction in $\dot{\mathrm{V}} / \mathrm{VCO}_{2}$ slope.

There were no significant differences in the change in heart rate with exercise $(53$ (5) $v 55$ (5) beats/min), change in systolic blood pressure with exercise (20 (4) $v 17$ (3) $\mathrm{mmHg}$ ), or respiratory exchange ratio at maximum exercise $(1.02(0.1) v 1.05(0.01)$

Balloon dilatation of the mitral valve increased the mitral valve area $<0.25 \mathrm{~cm}^{2}$ in four patients (nos 12, 15, 16, and 22). Repeat exercise testing at 10 weeks in these patients demonstrated no change in $\dot{\mathrm{V}} / \mathrm{V} \mathrm{CO}_{2}$ slope (before: 47 (8); after: $47(12)$ ) and a small non-significant increase in exercise duration (before: 250 (90); after: 300 (70) s).

\section{Discussion}

We have demonstrated that patients with rheumatic mitral stenosis have an increased

Table 2 Cardiorespiratory data obtained before and after balloon dilatation of the mitral valve $(n=10)$

\begin{tabular}{|c|c|c|c|c|}
\hline & \multirow{2}{*}{$\begin{array}{l}\text { Before balloon dilatation } \\
\text { of the mitral valve }\end{array}$} & \multicolumn{3}{|c|}{ After balloon dilatation of the mitral valve } \\
\hline & & $24 h$ & 10 days & 10 weeks \\
\hline $\begin{array}{l}\text { Exercise duration (s) } \\
\mathrm{Peak} \mathrm{VO}_{2}(\mathrm{ml} / \mathrm{kg} / \mathrm{min}) \\
\mathrm{VE}_{\mathrm{V}} \mathrm{COO}_{2} \\
\mathrm{RER}_{\max }\end{array}$ & $\begin{array}{l}380(200) \\
12(3 \cdot 5) \\
41(4) \\
1 \cdot 08(0 \cdot 1)\end{array}$ & $\begin{array}{c}355(210) \\
12(3 \cdot 7) \\
36(2 \cdot 9)^{\star} \\
0.96(0 \cdot 1)\end{array}$ & $\begin{array}{c}543(208)^{\star} \\
15(5 \cdot 5) \\
36(3)^{\star} \\
1(0 \cdot 1)\end{array}$ & $\begin{array}{c}685(256)^{\star} \\
15(4 \cdot 1) \dagger \\
34(2 \cdot 9)^{\star} \\
1 \cdot 08(0 \cdot 1)\end{array}$ \\
\hline
\end{tabular}

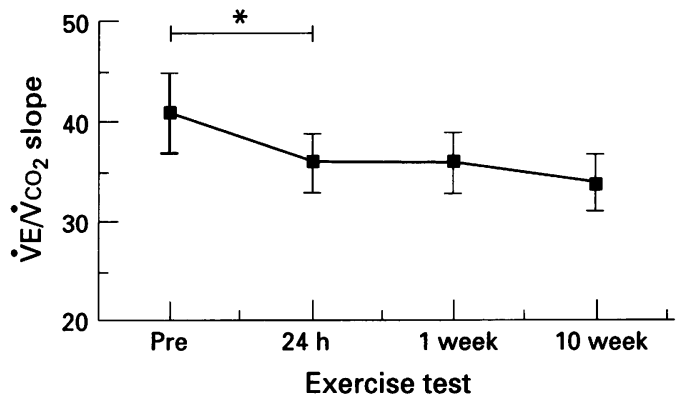

Figure 5 Time course of the mean (SD) change in $\dot{V} \mathrm{E} / \dot{V} \mathrm{CO}_{2}$ slope after balloon dilatation of the mitral valve $(n=10) .{ }^{*} P<0.01$.

ventilatory response to exercise. This is indicated by an increase in the slope of the linear relation between ventilation $(\dot{V} E)$ and $\dot{\mathrm{V}} \mathrm{CO}_{2}$ during exercise. As with $\mathrm{CHF}$ from other causes, the slope of this relation in mitral stenosis is related directly to exercise capacity expressed as peak $\dot{\mathrm{Vo}}_{2}$. Improved exercise duration after balloon dilatation of the mitral valve was associated with an increase in peak $\dot{\mathrm{VO}}_{2}$ and a decrease in the exercise $\dot{\mathrm{V}} / \mathrm{V} \mathrm{CO}_{2}$ slope. The change in slope occurred within 24 $\mathrm{h}$ of balloon dilatation and did not change again thereafter.

The exercise $\mathrm{VE} / \mathrm{V} \mathrm{CO}_{2}$ slope is increased in CHF of all causes. ${ }^{3}$ It reflects increased dead space ventilation which comprises anatomical dead space, physiological dead space, and apparatus dead space. In normal individuals the ratio of total ventilation to dead space ventilation decreases during exercise as tidal volume increases. When lung compliance is reduced by pulmonary congestion, tidal volumes are smaller and the ratio of total ventilation to dead space ventilation is increased. ${ }^{10}$ This increased anatomical dead space ventilation in patients with $\mathrm{CHF}$ accounts for only one third of the increased $\mathrm{VE} / \mathrm{V} \mathrm{CO}_{2}$ slope. ${ }^{5}$ The remainder reflects increased physiological dead space ventilation secondary to mismatching between ventilation and perfusion during exercise. ${ }^{5}$ As the $\dot{\mathrm{V}} / \mathrm{VCO}_{2}$ slope and peak $\mathrm{VO}_{2}$, are similarly related in patients with CHF and in those with mitral stenosis, the increased exercise ventilation in mitral stenosis probably reflects mismatching between ventilation and perfusion.

The distribution of resting lung ventilation and perfusion in patients with mitral stenosis has been studied extensively. There is an increase in relative perfusion to the apex of the lung ${ }^{11} 12$ and a reduction in ventilation of the lung bases. ${ }^{1113}$ These abnormalities are exaggerated after exercise. ${ }^{14}$ The resulting resting ventilation/perfusion ratios which are normally high in the lung apices and low in the bases are reversed, with a relatively uniform distribution of ventilation/perfusion ratio throughout the lung. This pattern of ventilation/perfusion abnormality is similar to patients with CHF from other causes. ${ }^{15}$

Static lung function may be abnormal in patients with mitral stenosis. The abnormalities are usually non-specific but include reductions in vital capacity and dynamic lung compliance, peripheral airway 
obstruction, and reduced pulmonary diffusion capacity. ${ }^{16}$

Improvement in the $\dot{\mathrm{V}} / \mathrm{V}_{\mathrm{CO}}$ slope could reflect a primary improvement in lung function. However, abnormalities in the alveolar/capillary membrane are not readily reversed and increases in vital capacity after balloon dilatation of the mitral valve do not correspond to the decrease in mean pulmonary artery pressure. ${ }^{16}$ These data and the rapid change we have observed in the $\dot{V} E / \mathrm{VCO}_{2}$ slope suggest that abnormality of the slope in mitral stenosis reflects impairment of the haemodynamic response to exercise and is not a feature of long standing pulmonary vascular change or a reflection of primary improvement in lung function.

In healthy individuals and patients with mild CHF and a peak $\dot{V O}_{2}>20 \mathrm{ml} / \mathrm{kg} / \mathrm{min}$ there is no relation between the $\dot{\mathrm{VE}} / \dot{\mathrm{V}} \mathrm{CO}_{2}$ slope and peak $\mathrm{V}_{2}{ }^{4}{ }^{4}$ This study demonstrates a persistence of the inverse relation between peak $\dot{\mathrm{VO}}_{2}$ and the $\dot{\mathrm{V}} / \dot{\mathrm{V}} \mathrm{CO}_{2}$ slope after balloon dilatation of the mitral valve. Reductions in pulmonary capillary wedge pressure, pulmonary artery pressure, and mitral valve gradient after balloon dilatation of the mitral valve are well recognised. ${ }^{17}$ These changes are associated with increases in exercise cardiac output, increased exercise duration, and improved symptomatic status at follow up. ${ }^{17}$ Mitral flow dynamics ${ }^{18}$ and right ventricular function $^{17}$ also improve rapidly after successful balloon dilatation of the mitral valve but not to normal. We postulate that continuing abnormalities in right ventricular function during exercise and residual valvar obstruction despite balloon dilatation of the mitral valve account for the persistence of the relation between peak $\dot{\mathrm{VO}}_{2}$ and $\dot{\mathrm{V}} / \dot{\mathrm{V}}_{\mathrm{CO}}$ slope.

We conclude that patients with rheumatic mitral stenosis have a similar increase in the $\dot{\mathrm{V}} \mathrm{E} / \mathrm{V} \mathrm{CO}_{2}$ slope as patients with heart failure from other causes and that this slope is directly related to exercise capacity. Successful balloon valvotomy is associated with an acute reduction in exercise $\dot{\mathrm{VE}} / \mathrm{V}_{\mathrm{CO}}$ slope and this may reflect increased ventilation/perfusion matching secondary to improved exercise haemodynamics.

\section{STUDY LIMITATIONS}

Measurement of arterial partial pressure of $\mathrm{CO}_{2}$ and exercise cardiac output are necessary to formally elucidate the mechanisms responsible for our observations. These measurements were not performed in this study as ethical approval was not available for invasive arterial monitoring.

APB is a British Heart Foundation junior research fellow.

1 Hall RJC. Rheumatic mitral valve disease. In: Julian DG Camm AJ, Fox KM, Hall RJC, Poole-Wilson PA, eds. Diseases of the heart. London: Balliere Tindall, Diseases of $1989: 751-69$.

2 Reed JW, Ablett M, Cotes JE. Ventilatory responses to exercise and to carbon dioxide in mitral stenosis before and after valvotomy: causes of tachypnoea. Clin $\mathrm{Sc}$ 1978;54:9-16.

3 Weber KT, Kinasewitz GT, Janicki JS, Fishman AP Oxygen utilization and ventilation during exercise in patients with chronic cardiac failure. Circulation 1982;65:1213-23.

4 Davies SW, Emery TM, Watling MIL, Wannamethee G Lipkin DP. A critical threshold of exercise capacity in the ventilatory response to exercise in heart failure. $B$ Heart $\mathcal{F} 1991 ; 65: 179-83$.

5 Buller NP, Poole-Wilson PA. Mechanism of the increased ventilatory response to exercise in patients with chronic ventilatory response to exercise in patients

6 Puri GD. Respiratory deadspace under anaesthesia in patients with mitral stenosis. European $\mathcal{f}$ Anaesthesiol patients with mitr

7 Weber KT, Kinasewitz GT, West JS, Janicki JS, Reichek N, Fishman AP. Long term vasodilator therapy with trimazosin in chronic cardiac failure. $N$ Engl $f \mathrm{Med}$ 1980;303:242-50.

8 Inoue K, Owaki T, Nakamura T, Kitamura F, Miyamoto $\mathrm{N}$. Clinical application of transvenous mitral commisurotomy by a new balloon catheter. $f$ Thora Cardiovasc Surg 1984;87:394-402.

9 Banning AP, Lewis NP, Northridge DB, Elbourne JS, Henderson AH. Perfusion/ventilation mismatch during exercise in chronic heart failure: an investigation of circulatory determinants. Br Heart f 1995;74:27-33.

10 Jones NL, Campbell EJ. Clinical Exercise Testing, 2nd ed. Philadelphia: WB Saunders, 1982: 27-31.

11 Dawson A, Rocamara JM, Morgan JB. Regional lung function in chronic pulmonary congestion with and withou mitral stenosis. Am Rev Respir Dis 1976;113:51-9.

12 Hughes JMB, Glazier JB, Rosenzweig DY, West JB Factors determining the distribution of pulmonary blood flow in patients with raised pulmonary venous pressure. Clin Sci 1969;37:847-58.

13 Jebavy P, Runczik I, Oppelt A, Tilsch J, Staneck V, Widimsky J. Regional pulmonary function in patients with mitral stenosis in relation to haemodynamic data. Br Heart f 1970;32:330-6.

14 Raine J, Bishop JM. The distribution of alveolar ventilation in mitral stenosis at rest and after exercise. Clin $S c i$ 1963;24:63-8.

15 Mohensifar Z, Amin DK, Shah PK. Regional distribution of lung perfusion and ventilation in patients with chronic congestive heart failure and its relationship to cardiopulcongestive heart failure and its relationship to cardiopul-
monary hemodynamics. Am Heart $f 1989 ; 117: 887-91$.

16 Yoshioka T, Nakanishi N, Okubo S, Kunieda T, Ishikura F, Nagata $S$. Improvement in pulmonary function in mitra stenosis after percutaneous transvenous mitral commisurotomy. Chest 1990;98:290-4.

17 Burger W, Kneissl GD, Kober G, Schrader R. Effect of balloon valvuloplasty for mitral stenosis on right ventricular function. Am $\mathcal{F}$ Cardiol 1993;71:994-6.

18 Tamai J, Nagata $S$, Akaike $M$, Ishikura $F$, Kimura $K$, Takamiya $\mathrm{M}$, et al. Improvement in exercise mitral flow dynamics during exercise after percutaneous transvenous mitral commisurotomy. Circulation 1990;81: 46-51. 
before any clinical component of their course; recent recommendations that all applicants to medical school should be screened, and immunised if appropriate, have far-reaching implications and have provoked controversy. ${ }^{17} 18$

In conclusion, among invasive cardiologists in the United Kingdom there is clear scope for improvement in vaccine uptake, particularly in completion of the immunisation regimen. Screening of patients, as recommended, should also be performed. Careful practice to avoid needle stick injury should continue and immunisation should also be offered to nursing and other ancillary staff caring for patients undergoing invasive cardiac procedures.

We thank Dr J Heptonstall, Consultant Medical Microbiologist, Public Health Laboratory Service Communicable Disease Surveillance Centre, London for invaluable advice before the preparation of this report. We also thank all those who completed and returned the questionnaire.

1 Recommendations of the Advisory Group on Hepatitis Protecting health care workers and patients from hepatitis Protecting health care work

2 Zuckermann A. Who should be immunised against hepatitis B? BMF 1984;289:1243

3 Recommendations of the Expert Advisory Group on AIDS Guidance for clinical health care workers: protection against infection with HIV/hepatitis B. HMSO, London 1990.

\section{CORRECTIONS}

Failure of "effective" treatment for heart failure to improve normal customary activity. $\mathcal{F} T \mathrm{Walsh}, R$ Andrews, $A$ Evans, $A \mathcal{F}$ Cowley (Br Heart $\mathcal{f}$ 1995;74: 373-6).

Exercise ventilation after balloon dilatation of the mitral valve. A P Banning, N P Lewis, $\mathcal{f} S$ Elborn, $R \mathcal{F}$ $C$ Hall (Br Heart $\mathcal{F} 1995 ; 74: 386-9)$.

We regret that the incorrect volume number was given in the strap lines and at the foot of the abstracts of these papers. The correct volume number is 74

Permanent pacemaker practice at a Scottish district general hospital between 1987 and 1994. $\mathcal{F} G$ Doherty, F Dawson, F Kerr

We regret that an error appeared in the second sentence of the discussion on page 477 of this article $(\mathrm{Br}$ Heart $\mathcal{F}$ 1995;73:475-8) which should have read, "Our average implantation rate over the 79 months $(130 / \mathrm{mil}$ lion population/year) compares with the United Kingdom national 1989 value of 148 /million population/year." $"$
4 Centers for Disease Control guidelines for prevention of HIV and hepatitis B viruses to health care and public safety workers. $M M W R$ 1989;38(suppl 56, 4-5):31-3.

5 Department of Health. Immunisation against infectious diseases. London: HMSO, 1992:110-9.

6 Polakoff S. Acute viral hepatitis B, reported to the Public Health Laboratory Service. F Infect 1990;20:163-8.

7 Heptonstall J. Outbreaks of hepatitis B virus infection associated with infected surgical staff. Communicable Disease Report 1991;1(8):R81-5.

8 Cartwright A. Professionals as poor responders: variations in and effects of response rates to questionnaires 1961-77. BMF 1978;ii:1419-21.

9 Editorial. Few physicians vaccinated against hepatitis B. Wis Med $\mathcal{F} 1989 ; 88: 14$.

10 Kinnersley P. Attitudes of general practitioners towards their vaccination against hepatitis B. BMf 1990;300:238.

11 Burden AD, Whorwell PJ. Poor uptake of hepatitis B immunisation amongst hospital-based health care staff. Postgrad Med F 1991;67:256-8.

12 Buss PW, McCabe M, Verrier Jones ER. Attitudes of paediatricians to HIV and hepatitis B virus infection. Arch Dis Child 1991;66:961-5.

13 Berridge DC, Galea MH, Evans DF, Pugh S, Hopkinson BR, Makin GS. Hepatitis B immunisation in vascula surgeons. Br f Surg 1990;77:585-6.

14 Williams JR, Flowerdew ADS. Uptake of immunisation against hepatitis $B$ among surgeons in Wessex Regional Health Authority. BMF 1990;301:154.

15 Le F, Porteous MJ. Operating practices of and precautions taken by orthopaedic surgeons to avoid infection with HIV and hepatitis B virus during surgery. BMF 1990; 301:167-9.

16 Lever AML. Treatment of the chronic hepatitis B virus carrier state. $\mathcal{F}$ Infect 1988;16:221-9.

17 Lever AML. Editorial: Hepatitis B and medical studen admission. $B M F$ 1994;308:870-1.

8 Kingman S. Hepatitis B status must be known for medical school. $B M \Im$ 1994;308:876.

The 1996 Annual General Meeting of the British Cardiac Society will take place at the Scottish Exhibition \& Conference Centre, Glasgow from 7 to 9 May.

The Fourth Annual Molecular Symposium at UCL Medical School on Ischaemic Preconditioning and Adaptation to Ischaemia will take place on 12 December 1995 in London. For further information please contact Jan Wenley, Symposium Administrator, Department of Molecular Pathology, 46 Cleveland Street, London W1P 6DB (tel: +44 171380 9343; fax: +44 1713873310 ). 